\title{
Endoscopic Submucosal Dissection vs Endoscopic Mucosal Resection for Colorectal Polyps. A Meta-Analysis
}

\author{
Xiong Chang Lim \\ National University of Singapore \\ Kameswara Rishi Yeshayahu Nistala \\ National University of Singapore \\ Cheng Han Ng ( $\nabla$ chenhanng@gmail.com) \\ National University of Singapore \\ Snow Yunni Lin \\ National University of Singapore \\ Darren Jun Hao Tan \\ National University of Singapore \\ Khek-Yu Ho \\ National University Health System \\ Mark Muthiah \\ National University of Singapore \\ Choon Seng Chong \\ National University of Singapore
}

\section{Systematic Review}

Keywords: endoscopic submucosal dissection, endoscopic mucosal resection, colorectal polyps, colorectal cancer, colonoscopy

Posted Date: January 14th, 2021

DOI: https://doi.org/10.21203/rs.3.rs-139442/v1

License: () (i) This work is licensed under a Creative Commons Attribution 4.0 International License. Read Full License 


\section{Abstract}

Background: This extensive meta-analysis sought to compare the surgical, histological, and oncological outcomes between endoscopic submucosal dissection (ESD) and endoscopic mucosal resection (EMR) in the treatment of colorectal polyps, with subgroup analysis comparing the efficacy of ESD and EMR between Japan and the rest of the world.

Methods: Embase and Medline databases were searched from inception to October 2020 in accordance with PRISMA guidelines for studies comparing en bloc, complete resection, margin involvement, resection time, need for additional surgery, complications, and recurrence rate of ESD with EMR.

Results: 281,344 colorectal polyps from 21 studies were included. When compared to EMR, the pooled analysis revealed ESD was associated with higher en bloc and complete resection rate, and lower lateral margin involvement and recurrence. ESD led to increased procedural time, need for additional surgery, and perforation risk. No significant difference in bleeding risk was found between the two groups. Meta-regression analysis suggested only right colonic polyps correlated with an increased perforation risk in ESD. Confounders including polyp size and invasion depth did not significantly influence the en bloc and complete resection rate, bleeding risk and recurrence. In subgroup analysis, Japan performed better than the rest of the world in both ESD and EMR with perforation risk of $4 \%$ and $0.0002 \%$, respectively, as compared to perforation risk of $8 \%$ and $1 \%$, respectively, in reports coming from rest of the world.

Conclusions: This meta-analysis demonstrated increased safety and efficacy of ESD and EMR done in Japan as compared with the rest of the world.

\section{Introduction}

In recent years, the incidence of colorectal polyps has increased drastically with the widespread implementation of national colorectal cancer (CRC) screening programs. CRC screening with colonoscopy provides the opportunity to identify and remove any precursor lesions ${ }^{1,2}$ and polypectomy has been shown to reduce the incidence and mortality of CRC. ${ }^{1,3,4}$ Currently, 2 major forms of polypectomy are performed, namely Endoscopic submucosal dissection (ESD) and Endoscopic mucosal resection (EMR) with the latter procedure favored by western countries.

ESD was first proposed in 1999 as an endoscopic resection technique for safe en bloc removal of superficial lesions in the upper GI tract. ${ }^{5}$ Although colorectal ESD is widely practiced in the Asian countries, the implementation of ESD in Western countries where endoscopic mucosal resection is preferred is still debatable. According to the 2015 European Society of Gastrointestinal Endoscopy (ESGE), ESD is strongly recommended when there is high suspicion of submucosal invasion as determined by morphologic factors and advanced surface pattern, especially in lesions greater than $20 \mathrm{~mm} .{ }^{6}$ Despite the technical difficulties faced, ESD is designed for en bloc resection of lesions in an attempt to achieve complete resection, reliable histopathological analysis, and reduced recurrence rate.

Previous meta-analyses and systematic reviews comparing ESD with EMR mainly focused on data reported from Asian countries with limited data coming from outside of Japan, without controlling for confounders or lesions $<20 \mathrm{~mm} .{ }^{7,8}$ Since then, numerous studies comparing between ESD and EMR have been reported from the West and other countries ${ }^{9-17}$ We sought to perform an expanded meta-analysis to include lesions $\leq 20 \mathrm{~mm}$, and incorporate regression analysis to control for confounders.

\section{Methods}

\section{Search Strategy and Inclusion Criteria}

A search was conducted with reference to the PRISMA methodology on October 4, 2020 in Medline and Embase ${ }^{18}$. Keywords and Mesh terms were employed in the search strategy relating to the 'Colorectal', 'Endoscopic Submucosal Dissection' and 'Endoscopic Mucosal Resection', the full list of terms included in the search can be found in the supplementary material 1. References were managed with Endnote X9. Two authors (XCL, KRYN) were involved in the sieving of the abstracts. Articles that compared between EMR and ESD for colorectal polyps were included in the search. Study designs included both retrospective and prospective cohorts, and case-controlled studies. Editorials, conferences abstracts, and commentaries were excluded in the review.

\section{Data Extraction}

Based on the pre-determined inclusion criterion, article selection was performed by two authors with consensus from an independent third author should discrepancies arise. Information pertaining to the demographics (country, sample size, age, gender, polyp location, polyp size, polyp macroscopic type and depth of cancer invasion) and outcomes were extracted. Outcomes were limited to en bloc resection, complete resection, lateral 
and vertical margin involvement, lymphovascular invasion, mean operation time, additional surgery required, perforation, bleeding, and recurrence. En bloc resection was defined as the resection of the lesion in a single specimen, and complete resection was defined as the resection of the lesion with no marginal involvement of neoplastic tissue, as assessed by the pathologist. Additional surgical operations performed were considered in cases with intra-operative complications as a result of ESD or EMR or those with technical difficulties. Bleeding was considered both intra-operative and postoperative, and perforation was considered when diagnosed endoscopically during resection or radiologically by the presence of free air. Recurrence was defined as the detection of local or secondary primary tumors on interval colonoscopy. When estimates of mean and standard deviation (SD) were not available for continuous data, well established formulae were used to estimate mean and SD from median and range. ${ }^{19}$

\section{Statistical Analysis and Quality Assessment}

Three type of analysis were performed in this review. Firstly, a meta-analysis of proportions was used to pool results from the individual arms (ESD and EMR) using a freeman turkey double arsine transformation ${ }^{20}$. The freeman turkey double arsine transformation is recommended for single arm metaanalysis and necessary to stabilize the variance. ${ }^{21}$ Next, comparative meta-analysis after a 0.5 continuity correction was to compare the difference in ESD and EMR, using risk ratios (RR) as the outcome of interest for dichotomous variables and weighted mean differences (WMD) for continuous variables $^{22}$. A 0.5 continuity correction was considered appropriate to incorporate 0 events into the meta-analysis. Regardless of heterogeneity measures $\left(I^{2}\right.$, tau, Cochran Q test), all analysis was performed in random effects with the Dersimonian and Laird model ${ }^{23,24}$ Region (Japan vs rest of the world) was defined with refences to the manuscript country of origin. Publication bias was assessed with harbord test and egger regression for dichotomous and continuous variables respectively when $>10$ studies were available. A univariate meta regression was also conducted with in random effects using the restricted maximum likelihood model with Kapp variance estimator to adjust for confounders in the outcomes ${ }^{25}$. A subgroup analysis was considered to compare between the articles originating from Japan and outside of Japan and a sensitivity analysis was performed to only include studies that have polyps size of $\geq 20 \mathrm{~mm}$. All articles were graded with the Newcastle Ottawa scale for cohort studies, grading articles on the domains of study group selection, study group comparability, and ascertainment of outcomes of interest. ${ }^{26}$

\section{Results}

A systematic search of the literature using our search strategy yielded 1,180 articles. After removal of duplicates, 895 were excluded based on study title and abstract, and 212 underwent full text review, of which 21 articles comparing ESD with EMR in resection of colorectal polyps were subsequently included in the meta-analysis (Fig. 1). ${ }^{9-17,27-38}$ In total, 12 originated from Japan ${ }^{27-38}$, five from European ${ }^{11-14,17}$, three from South Korea ${ }^{9}, 10,15$ and one from China ${ }^{16}$. Of the 21 studies, there were 17 retrospective cohort studies, two prospective cohort studies and two retrospective case-control studies. In total, 281,344 colorectal polyps were resected, of which 19,573 underwent ESD while 261,771 underwent EMR. Quality assessment of those included studies mostly scored 6-7. A summary of the study characteristics of the included articles can be found in the supplementary material 2.

\section{Overall results}

The summary of the results is found in table 1. The pooled analysis showed a higher rate of en bloc resection ( $R R=1.837 ; 95 \% \mathrm{Cl} 1.464$ to 2.305 ; $p<0.001)$, and a lower frequency of positive lateral margin involvement ( $R R=0.292 ; 95 \% \mathrm{Cl} 0.089$ to $0.995 ; p=0.042)$ in the ESD group than the EMR group. Publication bias was significant for en bloc resection rate $(p=0.0025)$. No significant difference in the rates of positive vertical margin involvement was observed between ESD and EMR groups ( $R R=4.368 ; 95 \% \mathrm{Cl} 0.409$ to $46.710 ; p=0.223$ ). However, the rate of complete resection was higher in the ESD compared to EMR groups ( $R R=1.504 ; 95 \% \mathrm{Cl} 1.041$ to $2.174 ; \mathrm{p}<0.03$ ). Significantly, the time taken for ESD was longer than EMR $(\mathrm{RR}=72.709 ; 95 \% \mathrm{Cl} 54.487$ to $90.931 ; \mathrm{p}<0.001)$. ESD group required more additional surgical operations relative to that of EMR group (RR=3.139; $95 \%$ Cl 1.360 to $7.243 ; p=0.007)$.

Compared to EMR, ESD shows a significant increased risk of perforation (RR=7.597; 95\% Cl 4.281 to $13.479 ; p<0.001)$ (Fig. 2), but no significant difference in the bleeding risk was observed between the two groups ( $R R=1.277 ; 95 \% \mathrm{Cl} 0.896$ to $1.820 ; p=0.175)($ Fig. 3$)$. The rate of recurrence in the ESD group was lower than that of the EMR group (RR=0.269; $95 \% \mathrm{Cl} 0.112$ to $0.648 ; \mathrm{p}=0.003$ ) (Fig. 4).

\section{Meta Regression}

The influence of the included covariates on en bloc resection, complete resection, risk of perforation and bleeding, and rate of recurrence evaluated by meta-regression are summarized in table 2. Meta-regression analysis for risk of perforation suggested that right colonic polyps $(\beta=7.731 ; 95 \% \mathrm{Cl} 4.965$ to 10.497; $p$ < 001) correlated with an increased risk in perforation in ESD (Fig. 5). Other factors including polyp size and depth of invasion, did not influence the en bloc resection rate, complete resection rate, the risk of bleeding, and recurrence rate. 
The results of the sensitivity analysis are summarized in supplementary material 3 and results were largely unchanged after a sensitivity analysis. When a sensitivity analysis was performed to include $\geq 20 \mathrm{~mm}$ colorectal polyps only, the pooled analysis revealed higher rate of en bloc resection (RR $=1.932 ; 95 \% \mathrm{Cl} 1.389$ to $2.688 ; \mathrm{p}<0.001)$, longer operation time $(\mathrm{RR}=3.247 ; 95 \% \mathrm{Cl} 59.249$ to $87.245 ; \mathrm{p}<0.001)$, higher risk of perforation $(\mathrm{RR}=4.513$; $95 \% \mathrm{Cl} 2.531$ to $8.046 ; \mathrm{p}<0.001)$ and lower recurrence rate $(\mathrm{RR}=0.191 ; 95 \% \mathrm{Cl} 0.085$ to $0.431 ; \mathrm{p}<0.001)$ in ESD compared to EMR groups. Furthermore, in the two studies included, more additional surgical operations were required $(R R=3.139 ; 95 \% \mathrm{Cl} 1.360$ to $7.243 ; p=0.007)$ in the $E S D$ than in the EMR groups.

\section{Subgroup Analysis by Region}

The results of the subgroup analysis comparing outcomes of ESD with EMR in Japan versus the rest of the world are presented in table 3.

ESD in Japan had an en bloc resection rate of $89 \%$ (95\% $\mathrm{Cl} 0.77$ to 0.97$)$, perforation risk of $4 \%$ ( $95 \% \mathrm{Cl} 0.01$ to 0.07 ), bleeding risk of $2.4 \%$ ( $95 \% \mathrm{Cl} 0.01$ to 0.04$)$ and recurrence rate of $1 \%(95 \% \mathrm{Cl} 0.01$ to 0.02$)$ while its EMR had an en bloc resection rate of $53 \%$ ( $95 \% \mathrm{Cl} 0.38$ to 0.67$)$, perforation risk of $0.0002 \%$ ( $95 \% \mathrm{CCl} 0.00$ to 0.00081 ), bleeding risk of $2.1 \%$ (95\% $\mathrm{Cl} 0.01$ to 0.03 ) and recurrence rate of $7 \%(95 \% \mathrm{Cl} 0.02$ to 0.15$)$. Comparing between the two techniques in Japan, ESD had higher en bloc resection rate ( $R R=1.658,95 \% \mathrm{Cl} 1.270$ to $2.165, \mathrm{p}<0.001$ ), perforation risk (RR=9.586, $95 \% \mathrm{Cl} 4.425$ to $20.768, p<0.001)$ and bleeding risk ( $R R=1.267,95 \% \mathrm{Cl} 1.174$ to $1.367, p<0.001)$ than $E M R$. Following sensitivity analysis, similar results were obtained, except ESD had lower recurrence rate than EMR ( $R R=0.204,95 \% \mathrm{Cl} 0.097$ to $0.429, p<0.001)$, and there was no difference in bleeding risk (RR=0.895, $95 \% \mathrm{Cl} 0.438$ to $1.829, \mathrm{p}=0.762$ ) between the two techniques.

With regards to studies from the rest of the world, ESD had an en bloc resection rate of $90 \%$ ( $95 \% \mathrm{Cl} 0.85$ to 0.94 ), perforation risk of $8 \%$ ( $95 \% \mathrm{Cl} 0.05$ to $0.12)$, bleeding risk of $5 \%(95 \% \mathrm{Cl} 0.02$ to 0.11$)$ and recurrence rate of $3 \%(95 \% \mathrm{Cl} 0.00$ to 0.08$)$ while EMR had an en bloc resection rate of $41 \%$ ( $95 \% \mathrm{Cl}$ 0.22 to 0.61 ), perforation risk of $1 \%(95 \% \mathrm{Cl} 0.00$ to 0.02$)$, bleeding risk of $3 \%(95 \% \mathrm{Cl} 0.01$ to 0.06$)$ and recurrence rate of $16 \%(95 \% \mathrm{Cl} 0.04$ to 0.32$)$. Comparing between the two techniques, ESD had higher en bloc resection rate ( $R R=2.201,95 \% \mathrm{Cl} 1.411$ to $3.433, p=0.001)$, perforation rate ( $R R=4.602$, $95 \% \mathrm{Cl} 2.729$ to $7.759, \mathrm{p}<0.001)$ and lower recurrence rate $(\mathrm{RR}=0.245,95 \% \mathrm{Cl} 0.073$ to $0.819, \mathrm{p}=0.022)$ than EMR. Following sensitivity analysis, similar results were obtained.

\section{Discussion}

The advancements in endoscopic resection techniques have resulted in the shift from radical surgery to minimally invasive and organ-sparing endoscopic resection techniques, such as ESD and EMR, for the treatment of colorectal lesions. With reference to 2015 ESGE guidelines, ESD should be considered for colorectal lesions larger than $20 \mathrm{~mm}$, with high suspicion of submucosal invasion, or those where en bloc resection by EMR are not feasible. ${ }^{6}$ Previous meta-analyses comparing ESD and EMR for colorectal polyps primarily reported data from Asian countries, with $72.7 \%$ of the published studies from Japan. ${ }^{7}$ Since then, several retrospective and prospective studies comparing ESD and EMR for the treatment of colorectal polyps have been published outside of Japan. The present study is the most extensive meta-analysis evaluating the surgical, histological, and oncological outcomes of ESD in comparison to EMR in the treatment of colorectal polyps. Nine out of 21 studies (42.9\%) on colorectal polyps included in this meta-analysis were conducted in countries outside of Japan. While ESD has been known to provide significantly better resection outcomes and lower recurrence rate, our analysis found that polyp size and depth of invasion did not significantly influence the en bloc and complete resection rate, bleeding and perforation risk, and recurrence rate in colorectal polyps that was not previously reported. Additionally, previous reviews were confined only to sessile lesions larger than $20 \mathrm{~mm} .7,8$ Our analysis also showed the increased proficiency in performing ESD and EMR in Japan as compared to the rest of the world.

Consistent with previous studies, ESD showed benefits in the technical, histological, and oncological outcomes. Pooled analysis showed higher rates of en bloc resection and complete resection in ESD than in EMR albeit significant publication bias $(\mathrm{p}=0.0025)$. En bloc resection offers the technical advantage of removing the entire pathologic specimen, thus allowing for detailed histologic evaluation. This results in an increase in the complete resection rate which in turn reduces the recurrence rate. Therefore, en bloc resection with ESD is favored as it provides curative treatment without the need for surgery for lesions with significant likelihood of submucosal invasion. ${ }^{39}$ However, the advantages of ESD come at the expense of longer procedural time, additional surgical operations, and increased perforation risk compared to EMR. ${ }^{7}$ The high rate of additional surgical operations for 
ESD is presumed to be due to the aggressive selection of ESD for T1 lesions. Although the perforation risk was higher with ESD, most perforations in the studies included were treated conservatively or endoscopically using endoclips. ${ }^{10,13,32,34,35,38}$

Meta-regression was performed to assess the risk factors that affect surgical, histological, and oncological outcomes. Our present analysis showed that polyp size did not affect the risk of perforation, which was reported otherwise in studies by Kim et al and Hong et al. ${ }^{40,41}$ Polyp size and depth of invasion were also not associated with significant change in en bloc and complete resection rate, risk of bleeding, and recurrence between ESD and EMR. Furthermore, the en bloc resection rate (before $R R=1.837,95 \% \mathrm{Cl} 1.464$ to $2.305, \mathrm{p}<0.001$; after $\mathrm{RR}=1.932,95 \% \mathrm{Cl} 1.389$ to 2.688 , $\mathrm{p}<0.001$ ) and recurrence rate (before $\mathrm{RR}=0.269,95 \% \mathrm{Cl} 0.112$ to $0.648, \mathrm{p}=0.003$; after $\mathrm{RR}=0.191,95 \% \mathrm{Cl} 0.085$ to $0.431 ; \mathrm{p}<0.001$ ) appeared comparable before and after the sensitivity analysis to $\geq 20 \mathrm{~mm}$ polyps. Instead, the risk of perforation was increased in patients with right colonic polyps and this was consistent with previous study which identified the technical difficulty and proficient endoscopic skills required to remove polyps from right colon safely. ${ }^{42}$ As such, training should ensure endoscopists achieve procedural proficiency in left sided lesions before proceeding to attempt right sided lesions. Other factors including polyp size and depth of invasion are less important criteria when deciding between EMR and ESD in skilled tertiary centers.

Despite the advantages of ESD, the data regarding the efficacy of colorectal ESD have been inconsistent and vary between Japan and the rest of the world. One of the reasons is the limitations to the implementation of ESD in other countries, which are in part due to the lack of expertise and training centers. To date, no meta-analysis comparing ESD and EMR between Japan and the rest of the world have been performed. Our single arm metaanalysis found that Japan performed better than the rest of the world in ESD and EMR. Significantly, perforation is a major concern in ESD. The perforation risk of ESD and EMR was $4 \%$ and $0.0002 \%$, respectively in Japan, and $8 \%$ and $1 \%$, respectively in the rest of the world. While there is an observed increase risk of perforation from Japan only studies (RR=9.586) compared to the rest of the world (RR=4.602), even after sensitivity analysis, the risk of perforation for ESD was only statistically higher in Japan only studies due to the very low risk of perforation in EMR in Japan. In addition, the challenges of doing ESD in difficult could have resulted in the higher perforation rate in ESD compared with EMR in Japan. Another important factor to consider is the recurrence rate of ESD and EMR which was $1 \%$ and $7 \%$, respectively in Japan and $3 \%$ and $27 \%$, respectively in the rest of the world following sensitivity analysis. The observed increase in recurrence rate from Japan only studies (RR=0.204) compared to the rest of the world $(R R=0.179)$ was due to the much lower recurrence rate of EMR in Japan as compared to the rest of the world. Overall, our results seem to favor studies from Japan and are in tandem with a single arm analysis of ESD only procedures with subgroup on region efficacy ${ }^{43}$. However, most of the studies originating from the rest of the world should be interpreted with the understanding that these studies are mainly from tertiary centers and the results may not be generalized to non-tertiary centers.

The potential of ESD resection is limited by the difficulty in conducting the procedure as the length of procedure for ESD even when performed by experienced endoscopists can be three times longer than that for EMR. ${ }^{44}$ However, the advancement in endoscopic resection equipment has been shown to shorten the procedure time despite a relatively short training duration. ${ }^{45}$ Using the cumulative sum (CUSUM) method, Miyakawa et al recently reported the use of Stag-Beetle Knife Jr for ESD in a Japan single-center study generated good learning curve to achieve satisfactory resection speed $\left(\mathrm{min} / \mathrm{cm}^{2}\right)$, which allowed the acquisition of proficient and safe skills within 120 cases. ${ }^{45}$ Other alternatives to ESD do exist, such as hybrid ESD and pre-cut EMR. This hybrid approach has been shown to have lower en bloc resection rate (68.4\% vs $91.0 \%$ ) and complete resection rate (60.6\% vs $82.9 \%$ ) than conventional ESD. ${ }^{43}$ Currently, underwater EMR has been thought to be a safe and effective method with higher rate of en bloc resection and lower rate of recurrence, ${ }^{46}$ but no head-to-head comparisons have been done between UMER and ESD.

\section{Strengths and Limitations}

The inclusion of 21 studies with a total of 281,344 polyps based on our search strategy and inclusion criteria represents the most extensive metaanalysis on this issue. However, as no randomized controlled trials comparing the performance between EMR and ESD have yet been conducted, this highlights the need for a randomized study to better understand the efficacy and safety of these techniques in the management of colorectal polyps. The evaluation of heterogeneity allowed us to compare the significant differences in the performance of ESD and EMR between Japan and the rest of the world.

Our meta-analysis has some limitations. While we aimed to decrease heterogeneity, the included articles used a variety of EMR techniques including standard EMR, piecemeal EMR (EPMR), EMR with small incision, EMR-precutting (EMR-P) and EMR-circumferential incision (EMR-Cl). This, however, was an acceptable confounding factor in previous meta-analysis analysis. Also, a major factor that we were unable to regress for was the procedural 
skills of each centers. ESD and EMR are largely operator dependent and we were only able to account for it in a subgroup analysis comparing between studies conducted in Japan and the rest of the world.

\section{Conclusion}

Evidence from this meta-analysis suggests that with appropriate training, ESD is preferred over EMR as the first-line therapy for resection of colorectal polyps, without restricting to lesions greater than $20 \mathrm{~mm}$ and those with high suspicion of submucosal invasion. Our overall findings are consistent with previous meta-analyses showing ESD is associated with higher rate of en bloc and complete resection, and lower recurrence compared to EMR, but at the cost of increased procedural time, need for additional surgical operations and perforation risk. This is coupled with the new finding that confounders including polyp size and invasion depth did not influence the rates of en bloc and complete resection, bleeding risk, and recurrence.

\section{Declarations}

\section{Acknowledgements:}

We would like to thank Dr Hiroaki Ikematsu of the Division of Science and Technology for Endoscopy, Exploratory Oncology Research \& Clinical Trial Center, National Cancer Center for his advice on the writing of the manuscript.

\section{Conflicts of Interests:}

All authors declare no conflict of interests.

\section{Funding Information:}

None.

\section{References}

1. Winawer SJ, Zauber AG, Ho MN, O'Brien MJ, Gottlieb LS, Sternberg SS, et al. Prevention of Colorectal Cancer by Colonoscopic Polypectomy. New England Journal of Medicine. 1993,329(27):1977-81.

2. Lim KT, Ng CH, Decruz GM, Lim TZ, Devi K, Tan K-K, et al. Barriers and facilitators towards colonoscopy: a qualitative systematic review. European Journal of Cancer Prevention. 9000;Publish Ahead of Print.

3. Zauber AG, Winawer SJ, O'Brien MJ, Lansdorp-Vogelaar I, van Ballegooijen M, Hankey BF, et al. Colonoscopic Polypectomy and Long-Term Prevention of Colorectal-Cancer Deaths. New England Journal of Medicine. 2012;366(8):687-96.

4. Siegel RL, Miller KD, Goding Sauer A, Fedewa SA, Butterly LF, Anderson JC, et al. Colorectal cancer statistics, 2020. CA Cancer J Clin. 2020;70(3):145-64.

5. Yamamoto H, Yube T, Isoda N, Sato Y, Sekine Y, Higashizawa T, et al. A novel method of endoscopic mucosal resection using sodium hyaluronate. Gastrointest Endosc. 1999;50(2):251-6.

6. Pimentel-Nunes P, Dinis-Ribeiro M, Ponchon T, Repici A, Vieth M, De Ceglie A, et al. Endoscopic submucosal dissection: European Society of Gastrointestinal Endoscopy (ESGE) Guideline. Endoscopy. 2015;47(9):829-54.

7. Arezzo A, Passera R, Marchese N, Galloro G, Manta R, Cirocchi R. Systematic review and meta-analysis of endoscopic submucosal dissection vs endoscopic mucosal resection for colorectal lesions. United European Gastroenterol J. 2016;4(1):18-29.

8. De Ceglie A, Hassan C, Mangiavillano B, Matsuda T, Saito Y, Ridola L, et al. Endoscopic mucosal resection and endoscopic submucosal dissection for colorectal lesions: A systematic review. Critical Reviews in Oncology/Hematology. 2016;104:138-55.

9. Lee EJ, Lee JB, Lee SH, Youk EG. Endoscopic treatment of large colorectal tumors: Comparison of endoscopic mucosal resection, endoscopic mucosal resection-precutting, and endoscopic submucosal dissection. Surgical Endoscopy. 2012;26(8):2220-30.

10. Kim YJ, Kim ES, Cho KB, Park KS, Jang BK, Chung WJ, et al. Comparison of clinical outcomes among different endoscopic resection methods for treating colorectal neoplasia. Digestive Diseases and Sciences. 2013;58(6):1727-36.

11. Acquistapace F, Maternini F, Snider L, Bellini O, Moglia P, Capretti P. Endoscopic treatment of superficial colorectal neoplasms. Retrospective analysis of a single center technique and results. II Giornale di chirurgia. 2015;36(6):247-50.

12. Emmanuel A, Gulati S, Burt M, Hayee B, Haji A. Combining eastern and western practices for safe and effective endoscopic resection of large complex colorectal lesions. European Journal of Gastroenterology and Hepatology. 2018;30(5):506-13.

13. Soliman H, Brieau B, Guillaumot MA, Leblanc S, Barret M, Camus M, et al. Invasive pit pattern, macronodule and depression are predictive factors of submucosal invasion in colorectal laterally spreading tumours from a Western population. United European Gastroenterology Journal.

2018;6(10):1569-77. 
14. Urban O, Falt P, Fojtik P, Andelova R. Comparison of endoscopic mucosal resection and endoscopic submucosal dissection in the treatment of flat neoplastic lesions in the rectum. Gastroenterologie a Hepatologie. 2018;72(3):193-8.

15. Jung J-S, Hong J-Y, Oh H-H, Kweon S-S, Lee J, Kim S-W, et al. Clinical outcomes of endoscopic resection for colorectal laterally spreading tumors with advanced histology. Surgical endoscopy. 2019;33(8):2562-71.

16. Liu C, Wu R, Sun X, Tao C, Liu Z. Risk factors for delayed hemorrhage after colonoscopic postpolypectomy: Polyp size and operative modality. JGH Open. 2019;3(1):61-4.

17. Benites H, Palacios F, Marín L, Bardalez P, Vásquez J, Alva E, et al. Closure of colonic deep mural injury and perforation with endoclips. Revista espanola de enfermedades digestivas : organo oficial de la Sociedad Espanola de Patologia Digestiva. 2020;112.

18. Moher D, Liberati A, Tetzlaff J, Altman DG, Group P. Preferred reporting items for systematic reviews and meta-analyses: the PRISMA statement. PLoS Med. 2009;6(7):e1000097-e.

19. Wan X, Wang W, Liu J, Tong T. Estimating the sample mean and standard deviation from the sample size, median, range and/or interquartile range. BMC Medical Research Methodology. 2014;14(1):135.

20. Nyaga VN, Arbyn M, Aerts M. Metaprop: a Stata command to perform meta-analysis of binomial data. Archives of Public Health. 2014;72(1):39.

21. Rousseau MJ, Evans JC. Key statistical assumptions and methods in one-arm meta-analyses with binary endpoints and low event rates, including a real-life example in the area of endoscopic colonic stenting. Cogent Medicine. 2017;4(1):1334318.

22. Harris R, Bradburn M, Deeks J, Harbord R, Altman D, Sterne J. metan: fixed- and random-effects meta-analysis. Stata Journal. 2008;8(1):3-28.

23. DerSimonian R, Laird N. Meta-analysis in clinical trials. Control Clin Trials. 1986;7(3):177-88.

24. Egger M, Smith GD, Schneider M, Minder C. Bias in meta-analysis detected by a simple, graphical test. BMJ. 1997;315(7109):629.

25. Harbord RM, Higgins JPT. Meta-Regression in Stata. The Stata Journal. 2008;8(4):493-519.

26. Wells G, Shea B, O'Connell J. The Newcastle-Ottawa Scale (NOS) for Assessing The Quality of Nonrandomised Studies in Meta-analyses. Ottawa Health Research Institute Web site. 2014;7.

27. Taku K, Sano Y, Fu K-I, Saito Y, Matsuda T, Uraoka T, et al. latrogenic perforation associated with therapeutic colonoscopy: a multicenter study in Japan. Journal of gastroenterology and hepatology. 2007;22(9):1409-14.

28. Tamegai Y, Saito Y, Masaki N, Hinohara C, Oshima T, Kogure E, et al. Endoscopic submucosal dissection: A safe technique for colorectal tumors. Endoscopy. 2007;39(5):418-22.

29. lizuka H, Okamura S, Onozato Y, Ishihara H, Kakizaki S, Mori M. Endoscopic submucosal dissection for colorectal tumors. Gastroenterologie Clinique et Biologique. 2009;33(10-11):1004-11.

30. Toyonaga T, Man-I M, Morita Y, Sanuki T, Yoshida M, Kutsumi H, et al. The new resources of treatment for early stage colorectal tumors: Emr with small incision and simplified endoscopic submucosal dissection. Digestive Endoscopy. 2009;21(SUPPL. 1):S31-S7.

31. Oka S, Tanaka S, Kanao H, Ishikawa $\mathrm{H}$, Watanabe $\mathrm{T}$, Igarashi $\mathrm{M}$, et al. Current status in the occurrence of postoperative bleeding, perforation and residual/local recurrence during colonoscopic treatment in Japan. Digestive endoscopy : official journal of the Japan Gastroenterological Endoscopy Society. 2010;22(4):376-80.

32. Saito Y, Fukuzawa M, Matsuda T, Fukunaga S, Sakamoto T, Uraoka T, et al. Clinical outcome of endoscopic submucosal dissection versus endoscopic mucosal resection of large colorectal tumors as determined by curative resection. Surgical Endoscopy. 2010;24(2):343-52.

33. Tajika M, Niwa Y, Bhatia V, Kondo S, Tanaka T, Mizuno N, et al. Comparison of endoscopic submucosal dissection and endoscopic mucosal resection for large colorectal tumors. European Journal of Gastroenterology and Hepatology. 2011;23(11):1042-9.

34. Kobayashi N, Yoshitake N, Hirahara Y, Konishi J, Saito Y, Matsuda T, et al. Matched case-control study comparing endoscopic submucosal dissection and endoscopic mucosal resection for colorectal tumors. Journal of Gastroenterology and Hepatology (Australia). 2012;27(4):728-33.

35. Sagawa T, Kakizaki S, lizuka H, Onozato Y, Sohara N, Okamura S, et al. Analysis of colonoscopic perforations at a local clinic and a tertiary hospital. World Journal of Gastroenterology. 2012;18(35):4898-904.

36. Terasaki M, Tanaka S, Oka S, Nakadoi K, Takata S, Kanao H, et al. Clinical outcomes of endoscopic submucosal dissection and endoscopic mucosal resection for laterally spreading tumors larger than 20mm. Journal of Gastroenterology and Hepatology (Australia). 2012;27(4):734-40.

37. Niikura R, Yasunaga H, Yamada A, Matsui H, Fushimi K, Hirata Y, et al. Factors predicting adverse events associated with therapeutic colonoscopy for colorectal neoplasia: a retrospective nationwide study in Japan. Gastrointestinal Endoscopy. 2016;84(6):971-82.e6.

38. Sato T, Fukuzawa M, Gotoda T, Moriyasu F. Comparison of clinical outcomes between colorectal EMR and ESD. Journal of Tokyo Medical University. 2016;74(2):154-62.

39. Tanaka S, Kashida H, Saito Y, Yahagi N, Yamano H, Saito S, et al. JGES guidelines for colorectal endoscopic submucosal dissection/endoscopic mucosal resection. Digestive endoscopy : official journal of the Japan Gastroenterological Endoscopy Society. 2015;27(4):417-34.

40. Kim ES, Cho KB, Park KS, Lee KI, Jang BK, Chung WJ, et al. Factors predictive of perforation during endoscopic submucosal dissection for the treatment of colorectal tumors. Endoscopy. 2011;43(7):573-8.

41. Hong SN, Byeon JS, Lee B-I, Yang D-H, Kim J, Cho KB, et al. Prediction model and risk score for perforation in patients undergoing colorectal endoscopic submucosal dissection. Gastrointestinal Endoscopy. 2016;84(1):98-108. 
42. Nishiyama H, Isomoto H, Yamaguchi N, Fukuda E, Ikeda K, Ohnita K, et al. Endoscopic submucosal dissection for colorectal epithelial neoplasms. Diseases of the colon and rectum. 2010;53(2):161-8.

43. Fuccio L, Hassan C, Ponchon T, Mandolesi D, Farioli A, Cucchetti A, et al. Clinical outcomes after endoscopic submucosal dissection for colorectal neoplasia: a systematic review and meta-analysis. Gastrointest Endosc. 2017;86(1):74-86.e17.

44. Fujiya M, Tanaka K, Dokoshi T, Tominaga M, Ueno N, Inaba Y, et al. Efficacy and adverse events of emr and endoscopic submucosal dissection for the treatment of colon neoplasms: A meta-analysis of studies comparing emr and endoscopic submucosal dissection. Gastrointestinal Endoscopy. 2015;81(3):583-95.

45. Miyakawa A, Kuwai T, Sakuma Y, Kubota M, Nakamura A, Itobayashi E, et al. Learning curve for endoscopic submucosal dissection of early colorectal neoplasms with a monopolar scissor-type knife: use of the cumulative sum method. Scandinavian Journal of Gastroenterology. 2020;55(10):1234-42.

46. Choi AY, Moosvi ZM, Shah S, Roccato MK, Wang AY, Hamerski CM, et al. Underwater versus conventional endoscopic mucosal resection for colorectal polyps: a systematic review and meta-analysis. Gastrointestinal Endoscopy. 2020.

\section{Tables}

Table 1. Pooled proportions and comparative meta-analysis of ESD and EMR

\begin{tabular}{|c|c|c|c|c|c|c|c|c|}
\hline & $\begin{array}{l}\text { Total } \\
\text { Papers }\end{array}$ & $\begin{array}{l}\text { Sample Size } \\
\text { (ESD) }\end{array}$ & $\begin{array}{l}\text { Pooled } \\
\text { Proportions }\end{array}$ & $\begin{array}{l}\text { Sample Size } \\
\text { (EMR) }\end{array}$ & $\begin{array}{l}\text { Pooled } \\
\text { Proportions }\end{array}$ & $\mathrm{RR}(\mathrm{Cl})$ & $\begin{array}{l}P \\
\text { value }\end{array}$ & $\begin{array}{l}\text { Publication } \\
\text { Bias }\end{array}$ \\
\hline \multirow[t]{2}{*}{ En bloc resection } & 11 & 1641 & $89 \%$ & 1411 & $47 \%$ & 1.837 & $<0.001$ & 0.0025 \\
\hline & & & $(0.83-0.94)$ & & $(0.36-0.59)$ & $\begin{array}{l}(1.464- \\
2.305)\end{array}$ & & \\
\hline \multirow{2}{*}{$\begin{array}{l}\text { Positive lateral } \\
\text { margin }\end{array}$} & 2 & 123 & $3 \%$ & 187 & $14 \%$ & 0.292 & 0.042 & - \\
\hline & & & $(0.01-0.06)$ & & $(0.09-0.19)$ & $\begin{array}{l}(0.089- \\
0.995)\end{array}$ & & \\
\hline \multirow{2}{*}{$\begin{array}{l}\text { Positive vertical } \\
\text { margin }\end{array}$} & 1 & 38 & $5 \%$ & 83 & $1 \%$ & 4.368 & 0.223 & - \\
\hline & & & $(0.00-0.17)$ & & $(0.00-0.07)$ & $\begin{array}{l}(0.409- \\
46.710)\end{array}$ & & \\
\hline \multirow{2}{*}{$\begin{array}{l}\text { Complete } \\
\text { resection }\end{array}$} & 8 & 918 & $82 \%$ & 1012 & $56 \%$ & 1.504 & 0.03 & - \\
\hline & & & $(0.74-0.88)$ & & $(0.34-0.77)$ & $\begin{array}{l}(1.041- \\
2.174)\end{array}$ & & \\
\hline \multirow{2}{*}{$\begin{array}{l}\text { Lymphovsacular } \\
\text { invasion }\end{array}$} & 1 & 54 & $6 \%$ & 23 & $0 \%$ & 4.352 & 0.315 & - \\
\hline & & & $(0.03-0.13)$ & & $(0.00-0.04)$ & $\begin{array}{l}(0.248- \\
76.483)\end{array}$ & & \\
\hline \multirow{2}{*}{$\begin{array}{l}\text { Mean procedural } \\
\text { time }\end{array}$} & 8 & 1087 & - & 838 & - & 72.709 & $<0.001$ & - \\
\hline & & & & & & $\begin{array}{l}(54.487 \text { - } \\
90.931)\end{array}$ & & \\
\hline \multirow[t]{2}{*}{ Additional surgery } & 2 & 99 & $13 \%$ & 153 & $5 \%$ & 3.139 & 0.007 & - \\
\hline & & & $(0.07-0.21)$ & & $(0.02-0.09)$ & $\begin{array}{l}(1.360- \\
7.243)\end{array}$ & & \\
\hline \multirow[t]{2}{*}{ Perforation } & 18 & 19470 & $5 \%$ & 260901 & $0 \%$ & 7.597 & $<0.001$ & 0.301 \\
\hline & & & $(0.03-0.09)$ & & $(0.00-0.01)$ & $\begin{array}{l}(4.281- \\
13.479)\end{array}$ & & \\
\hline \multirow[t]{2}{*}{ Bleeding } & 14 & 20048 & $3 \%$ & 257065 & $3 \%$ & 1.277 & 0.175 & 0.139 \\
\hline & & & $(0.02-0.05)$ & & $(0.02-0.04)$ & $\begin{array}{l}(0.896- \\
1.820)\end{array}$ & & \\
\hline \multirow[t]{2}{*}{ Recurrences } & 12 & 1822 & $2 \%$ & 37721 & $10 \%$ & 0.269 & 0.003 & 0.725 \\
\hline & & & $(0.01-0.03)$ & & $(0.04-0.17)$ & $\begin{array}{l}(0.112- \\
0.648)\end{array}$ & & \\
\hline
\end{tabular}

ESD: endoscopic submucosal dissection; EMR: endoscopic mucosal resection; Cl: confidence interval 


\begin{tabular}{|c|c|c|c|c|c|c|c|c|c|c|c|c|c|c|c|}
\hline & \multicolumn{3}{|c|}{ En bloc resection } & \multicolumn{3}{|c|}{ Complete resection } & \multicolumn{2}{|c|}{ Perforation } & \multirow[b]{2}{*}{$\begin{array}{l}P \\
\text { value }\end{array}$} & \multicolumn{2}{|c|}{ Bleeding } & \multicolumn{4}{|c|}{ Recurrence } \\
\hline & $\mathbf{n}$ & $\begin{array}{l}\text { Beta } \\
\text { (Cl) }\end{array}$ & $\begin{array}{l}P \\
\text { value }\end{array}$ & $\mathbf{n}$ & Beta (Cl) & $\begin{array}{l}P \\
\text { value }\end{array}$ & $\mathrm{n}$ & $\begin{array}{l}\text { Beta } \\
\text { (Cl) }\end{array}$ & & $\mathbf{n}$ & Beta (Cl) & $\begin{array}{l}\mathrm{P} \\
\text { value }\end{array}$ & $\mathrm{n}$ & $\begin{array}{l}\text { Beta } \\
\text { (Cl) }\end{array}$ & $\begin{array}{l}\mathrm{P} \\
\text { value }\end{array}$ \\
\hline \multirow[t]{2}{*}{ Age } & 8 & -0.017 & 0.785 & 5 & -0.010 & 0.944 & 9 & 0.073 & 0.535 & 8 & -0.201 & 0.197 & 8 & 0.254 & 0.078 \\
\hline & & $\begin{array}{l}(-0.168- \\
0.133)\end{array}$ & & & $\begin{array}{l}(-0.426- \\
0.406)\end{array}$ & & & $\begin{array}{l}(-0.191- \\
0.336)\end{array}$ & & & $\begin{array}{l}(-0.540- \\
0.138)\end{array}$ & & & $\begin{array}{l}(-0.039- \\
0.547)\end{array}$ & \\
\hline \multirow[t]{3}{*}{ Gender } & 6 & -6.023 & 0.384 & 4 & -20.662 & 0.419 & 8 & -7.868 & 0.224 & 7 & -4.446 & 0.647 & 6 & -9.096 & 0.659 \\
\hline & & $(-23.152$ & & & $\begin{array}{l}(-108.758 \\
-67.434)\end{array}$ & & & $\underline{(-22.078}$ & & & $\begin{array}{l}(-27.915- \\
19.022)\end{array}$ & & & $(-62.174$ & \\
\hline & & 11.106) & & & & & & $6.342)$ & & & & & & 43.982) & \\
\hline \multirow[t]{2}{*}{ Polyp size } & 10 & 0.242 & 0.390 & 6 & -0.034 & 0.217 & 10 & -0.034 & 0.378 & 9 & -0.041 & 0.498 & 8 & 0.077 & 0.369 \\
\hline & & $\begin{array}{l}(-0.037- \\
0.086)\end{array}$ & & & $\begin{array}{l}(-0.098- \\
0.030)\end{array}$ & & & $\begin{array}{l}(-0.117- \\
0.049)\end{array}$ & & & $\begin{array}{l}(-0.177- \\
0.095)\end{array}$ & & & $\begin{array}{l}(-0.118- \\
0.272)\end{array}$ & \\
\hline \multirow{2}{*}{$\begin{array}{l}\text { Lateral } \\
\text { spreading } \\
\text { tumor }\end{array}$} & 10 & 1.262 & 0.248 & 7 & -0.481 & 0.779 & 11 & -2.324 & 0.136 & 9 & -0.680 & 0.753 & 9 & 3.827 & 0.185 \\
\hline & & $\begin{array}{l}(-1.072- \\
3.596)\end{array}$ & & & $\begin{array}{l}(-4.655- \\
3.693)\end{array}$ & & & $\begin{array}{l}(-5.536- \\
0.888)\end{array}$ & & & $\begin{array}{l}(-5.586- \\
4.226)\end{array}$ & & & $\begin{array}{l}(-2.323- \\
9.977)\end{array}$ & \\
\hline \multirow[t]{2}{*}{ Right colon } & 8 & 1.247 & 0.387 & 5 & 2.373 & 0.103 & 8 & 7.731 & $<0.001$ & 7 & 1.688 & 0.771 & 6 & -8.739 & 0.246 \\
\hline & & $\begin{array}{l}(-2.024- \\
4.517)\end{array}$ & & & $\begin{array}{l}(-0.881- \\
5.626)\end{array}$ & & & $\begin{array}{l}(4.965- \\
10.497)\end{array}$ & & & $\begin{array}{l}(-12.442- \\
15.817)\end{array}$ & & & $\begin{array}{l}(-26.616 \\
-9.139)\end{array}$ & \\
\hline \multirow[t]{2}{*}{ Colon } & 7 & -1.803 & 0.145 & 4 & -1.914 & 0.26 & 8 & 0.759 & 0.654 & 6 & 6.649 & 0.194 & 7 & -1.102 & 0.473 \\
\hline & & $\begin{array}{l}(-4.486- \\
0.880)\end{array}$ & & & $\begin{array}{l}(-7.213- \\
3.385)\end{array}$ & & & $\begin{array}{l}(-3.184- \\
4.701)\end{array}$ & & & $\begin{array}{l}(-5.182- \\
18.480)\end{array}$ & & & $\begin{array}{l}(-4.754- \\
2.551)\end{array}$ & \\
\hline \multirow[t]{2}{*}{ Rectum } & 7 & 1.803 & 0.145 & 4 & 1.914 & 0.26 & 8 & -0.759 & 0.654 & 6 & -6.649 & 0.194 & 7 & 1.102 & 0.473 \\
\hline & & $\begin{array}{l}(-0.880- \\
4.486)\end{array}$ & & & $\begin{array}{l}(-3.385- \\
7.213)\end{array}$ & & & $\begin{array}{l}(-4.701- \\
3.184)\end{array}$ & & & $\begin{array}{l}(-18.480- \\
5.182)\end{array}$ & & & $\begin{array}{l}(-2.551- \\
4.754)\end{array}$ & \\
\hline \multirow{2}{*}{$\begin{array}{l}\text { Submucosal } \\
\text { invasion }\end{array}$} & 8 & -0.004 & 0.431 & 5 & -0.006 & 0.253 & 9 & 0.001 & 0.956 & 8 & -0.016 & 0.061 & 7 & -6.508 & 0.471 \\
\hline & & $\begin{array}{l}(-0.014- \\
0.007)\end{array}$ & & & $\begin{array}{l}(-0.020- \\
0.008)\end{array}$ & & & $\begin{array}{l}(-0.049- \\
0.051)\end{array}$ & & & $\begin{array}{l}(-0.033- \\
0.001)\end{array}$ & & & $\begin{array}{l}(-27.976 \\
- \\
14.960)\end{array}$ & \\
\hline \multirow{2}{*}{$\begin{array}{l}\text { Muscularis } \\
\text { propria } \\
\text { invasion }\end{array}$} & 8 & -5.870 & 0.272 & 5 & -0.157 & 0.983 & 9 & 6.731 & 0.706 & 8 & -109.836 & 0.783 & - & - & - \\
\hline & & $\begin{array}{l}(-17.738 \\
-5.998)\end{array}$ & & & $\begin{array}{l}(-21.715- \\
21.401)\end{array}$ & & & $\begin{array}{l}(-33.772 \\
- \\
47.234)\end{array}$ & & & $\begin{array}{l}(-1040.943 \\
-821.272)\end{array}$ & & & & \\
\hline
\end{tabular}

ESD: endoscopic submucosal dissection; EMR: endoscopic mucosal resection; Cl: confidence interval

Table 3. Subgroup analysis (Japan and rest of the world) of pooled proportions and comparative meta-analysis of ESD and EMR 


\begin{tabular}{|c|c|c|c|c|c|c|c|c|c|c|}
\hline & $\begin{array}{l}\text { Japan } \\
\text { Papers }\end{array}$ & $\begin{array}{l}\text { Pooled } \\
\text { Proportions } \\
\text { (ESD) }\end{array}$ & $\begin{array}{l}\text { Pooled } \\
\text { Proportions } \\
\text { (EMR) }\end{array}$ & $\mathrm{RR}(\mathrm{Cl})$ & $\begin{array}{l}\mathrm{P} \\
\text { value }\end{array}$ & $\begin{array}{l}\text { Rest of } \\
\text { the World } \\
\text { Papers }\end{array}$ & $\begin{array}{l}\text { Pooled } \\
\text { Proportions } \\
\text { (ESD) }\end{array}$ & $\begin{array}{l}\text { Pooled } \\
\text { Proportions } \\
\text { (EMR) }\end{array}$ & $\mathrm{RR}(\mathrm{Cl})$ & $\begin{array}{l}P \\
\text { value }\end{array}$ \\
\hline \multicolumn{11}{|l|}{ Overall Results } \\
\hline \multirow{2}{*}{$\begin{array}{l}\text { En bloc } \\
\text { resection }\end{array}$} & \multirow[t]{2}{*}{6} & $89 \%$ & $53 \%$ & 1.658 & \multirow[t]{2}{*}{$<0.001$} & \multirow[t]{2}{*}{5} & $90 \%$ & $41 \%$ & 2.201 & \multirow[t]{2}{*}{0.001} \\
\hline & & $(0.77-0.97)$ & $(0.38-0.67)$ & $\begin{array}{l}(1.270- \\
2.165)\end{array}$ & & & $(0.85-0.94)$ & $(0.22-0.61)$ & $\begin{array}{l}(1.411 \text { - } \\
3.433)\end{array}$ & \\
\hline \multirow{2}{*}{$\begin{array}{l}\text { Positive lateral } \\
\text { margin }\end{array}$} & \multirow[t]{2}{*}{2} & $3 \%$ & $14 \%$ & 0.292 & \multirow[t]{2}{*}{0.042} & \multirow[t]{2}{*}{-} & \multirow[t]{2}{*}{-} & \multirow[t]{2}{*}{-} & \multirow[t]{2}{*}{-} & \multirow[t]{2}{*}{-} \\
\hline & & $(0.00-0.06)$ & $(0.09-0.19)$ & $\begin{array}{l}(0.089- \\
0.955)\end{array}$ & & & & & & \\
\hline \multirow{2}{*}{$\begin{array}{l}\text { Positive vertical } \\
\text { margin }\end{array}$} & \multirow[t]{2}{*}{1} & $5 \%$ & $1 \%$ & 4.368 & \multirow[t]{2}{*}{0.223} & \multirow[t]{2}{*}{-} & \multirow[t]{2}{*}{-} & \multirow[t]{2}{*}{-} & \multirow[t]{2}{*}{-} & \multirow[t]{2}{*}{-} \\
\hline & & $(0.01-0.17)$ & $(0.00-0.05)$ & $\begin{array}{l}(0.409- \\
46.710)\end{array}$ & & & & & & \\
\hline \multirow{2}{*}{$\begin{array}{l}\text { Complete } \\
\text { resection }\end{array}$} & \multirow[t]{2}{*}{2} & $79 \%$ & $53 \%$ & 1.452 & \multirow[t]{2}{*}{$<0.001$} & \multirow[t]{2}{*}{6} & $85 \%$ & $59 \%$ & 1.562 & 0.098 \\
\hline & & $(0.73-0.84)$ & $(0.48-0.58)$ & $\begin{array}{l}(1.303- \\
1.618)\end{array}$ & & & $(0.78-0.91)$ & $(0.27-0.88)$ & $\begin{array}{l}(0.921- \\
2.650)\end{array}$ & \\
\hline Lymphovsacular & 1 & $6 \%$ & $0 \%$ & 4.352 & 0.315 & - & - & - & - & - \\
\hline invasion & & $(0.03-0.13)$ & $(0.00-0.04)$ & $\begin{array}{l}(0.248- \\
76.483)\end{array}$ & & & & & & \\
\hline Mean & 4 & - & - & 72.106 & $<0.001$ & 4 & - & - & 73.916 & $<0.001$ \\
\hline & & & & $(48.831$ & & & & & (36.075- & \\
\hline & & & & 95.382) & & & & & & \\
\hline Additional & 2 & $13 \%$ & $5 \%$ & 3.139 & 0.007 & - & - & - & - & - \\
\hline & & $(0.07-0.21)$ & $(0.02-0.09)$ & $\begin{array}{l}(1.360- \\
7.243)\end{array}$ & & & & & & \\
\hline Perforation & 11 & $4 \%$ & $0.0002 \%$ & 9.586 & $<0.001$ & 7 & $8 \%$ & $1 \%$ & 4.602 & $<0.001$ \\
\hline & & $(0.01-0.07)$ & $\begin{array}{l}(0.00- \\
0.00081)\end{array}$ & $\begin{array}{l}(4.425- \\
20.768)\end{array}$ & & & $(0.05-0.12)$ & $(0.00-0.02)$ & $\begin{array}{l}(2.729- \\
7.759)\end{array}$ & \\
\hline Bleeding & 8 & $2.4 \%$ & $2.1 \%$ & 1.267 & $<0.001$ & 6 & $5 \%$ & $3 \%$ & 1.986 & 0.188 \\
\hline & & $(0.01-0.04)$ & $(0.01-0.03)$ & $\begin{array}{l}(1.174- \\
1.367)\end{array}$ & & & $(0.02-0.11)$ & $(0.01-0.06)$ & $\begin{array}{l}(0.716- \\
5.508)\end{array}$ & \\
\hline Recurrences & 7 & $1 \%$ & $7 \%$ & 0.274 & 0.06 & 5 & $3 \%$ & $16 \%$ & 0.245 & 0.022 \\
\hline & & $(0.01-0.02)$ & $(0.02-0.15)$ & $\begin{array}{l}(0.071- \\
1.054)\end{array}$ & & & $(0.00-0.08)$ & $(0.04-0.32)$ & $\begin{array}{l}(0.073- \\
0.819)\end{array}$ & \\
\hline Sensitivity Analysi & $(\geq 20 \mathrm{~m}$ & only) & & & & & & & & \\
\hline $\begin{array}{l}\text { En bloc } \\
\text { resection }\end{array}$ & 4 & $82 \%$ & $50 \%$ & 1.645 & 0.004 & 2 & $91 \%$ & $33 \%$ & 2.668 & $<0.001$ \\
\hline & & $(0.72-0.91)$ & $(0.33-0.67)$ & $\begin{array}{l}(1.174- \\
2.306)\end{array}$ & & & $(0.88-0.93)$ & $(0.28-0.37)$ & $\begin{array}{l}(1.752- \\
4.063)\end{array}$ & \\
\hline Positive lateral & 2 & $3 \%$ & $14 \%$ & 0.292 & 0.042 & - & - & - & - & - \\
\hline & & $(0.00-0.06)$ & $(0.09-0.19)$ & $\begin{array}{l}(0.089- \\
0.955)\end{array}$ & & & & & & \\
\hline Positive vertical & 1 & $5 \%$ & $1 \%$ & 4.368 & 0.223 & - & - & - & - & - \\
\hline & & $(0.01-0.17)$ & $(0.00-0.07)$ & $\begin{array}{l}(0.409- \\
46.710)\end{array}$ & & & & & & \\
\hline $\begin{array}{l}\text { Complete } \\
\text { resection }\end{array}$ & 2 & $79 \%$ & $53 \%$ & 1.452 & $<0.001$ & 2 & $90 \%$ & $77 \%$ & 1.613 & 0.647 \\
\hline & & $(0.73-0.84)$ & $(0.48-0.58)$ & $\begin{array}{l}(1.303- \\
1.618)\end{array}$ & & & $(0.87-0.93)$ & $(0.73-0.82)$ & $\begin{array}{l}(0.209- \\
12.452)\end{array}$ & \\
\hline Lymphovsacular & 2 & $6 \%$ & $0 \%$ & 4.352 & 0.315 & - & - & - & - & - \\
\hline invasion & & $(0.03-0.13)$ & $(0.00-0.04)$ & $\begin{array}{l}(0.248- \\
76.483)\end{array}$ & & & & & & \\
\hline Mean & 2 & - & - & 69.167 & $<0.001$ & 1 & - & - & 82.700 & $<0.001$ \\
\hline
\end{tabular}




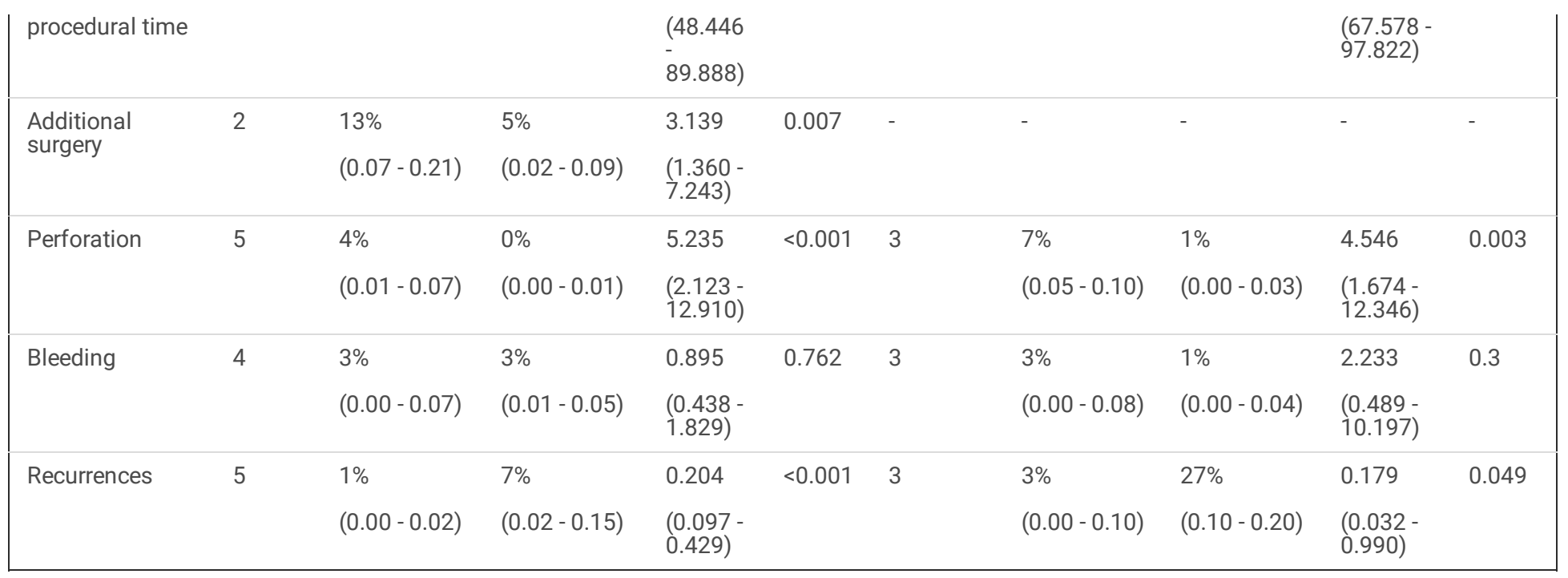

ESD: endoscopic submucosal dissection; EMR: endoscopic mucosal resection; RR: relative risk; Cl: confidence interval

\section{Figures}



Figure 1

PRISMA flow diagram of included articles 
Study

ID

RR $(95 \% \mathrm{Cl})$

Weight

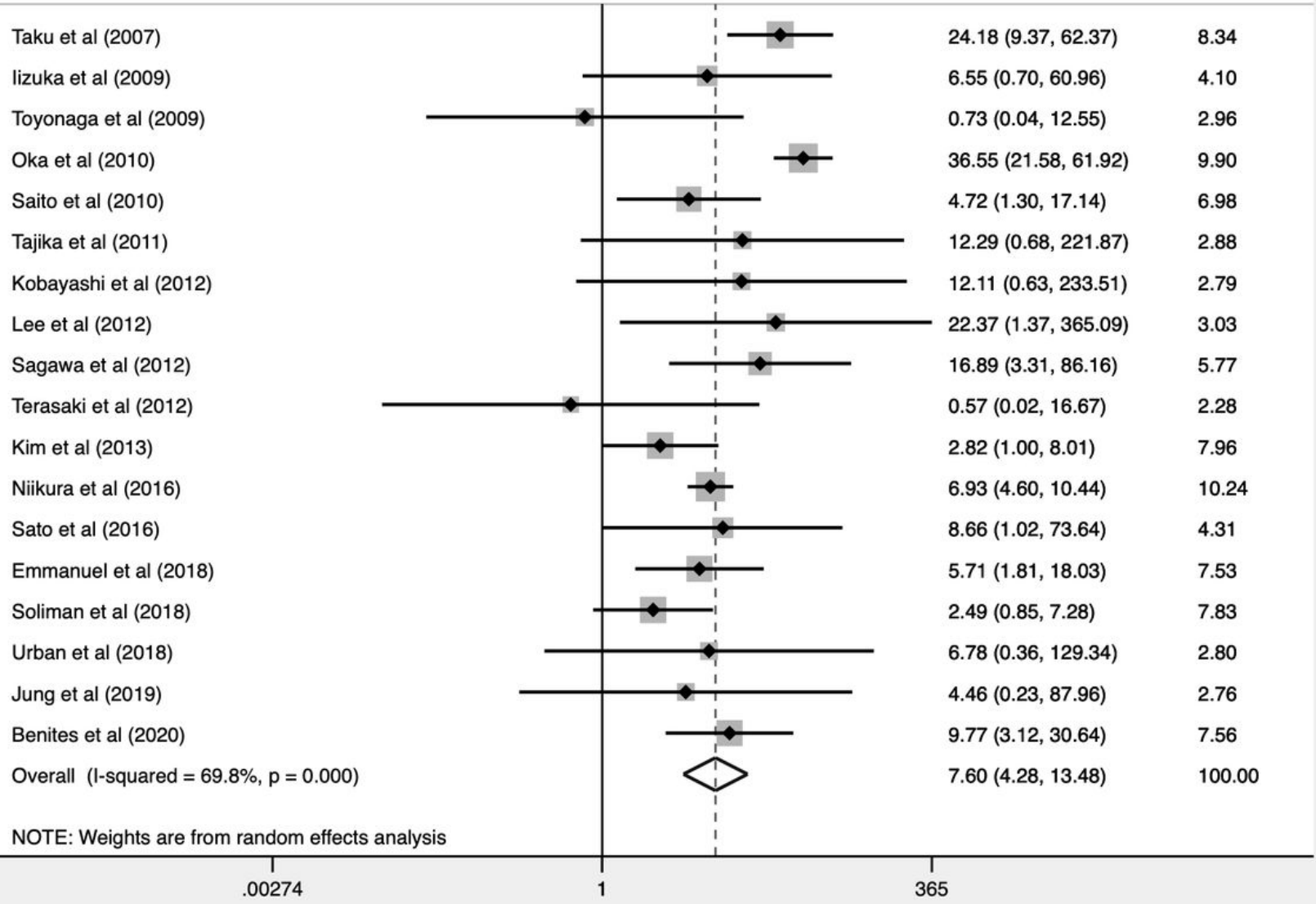

\section{Figure 2}

Forest plot for risk of perforation 


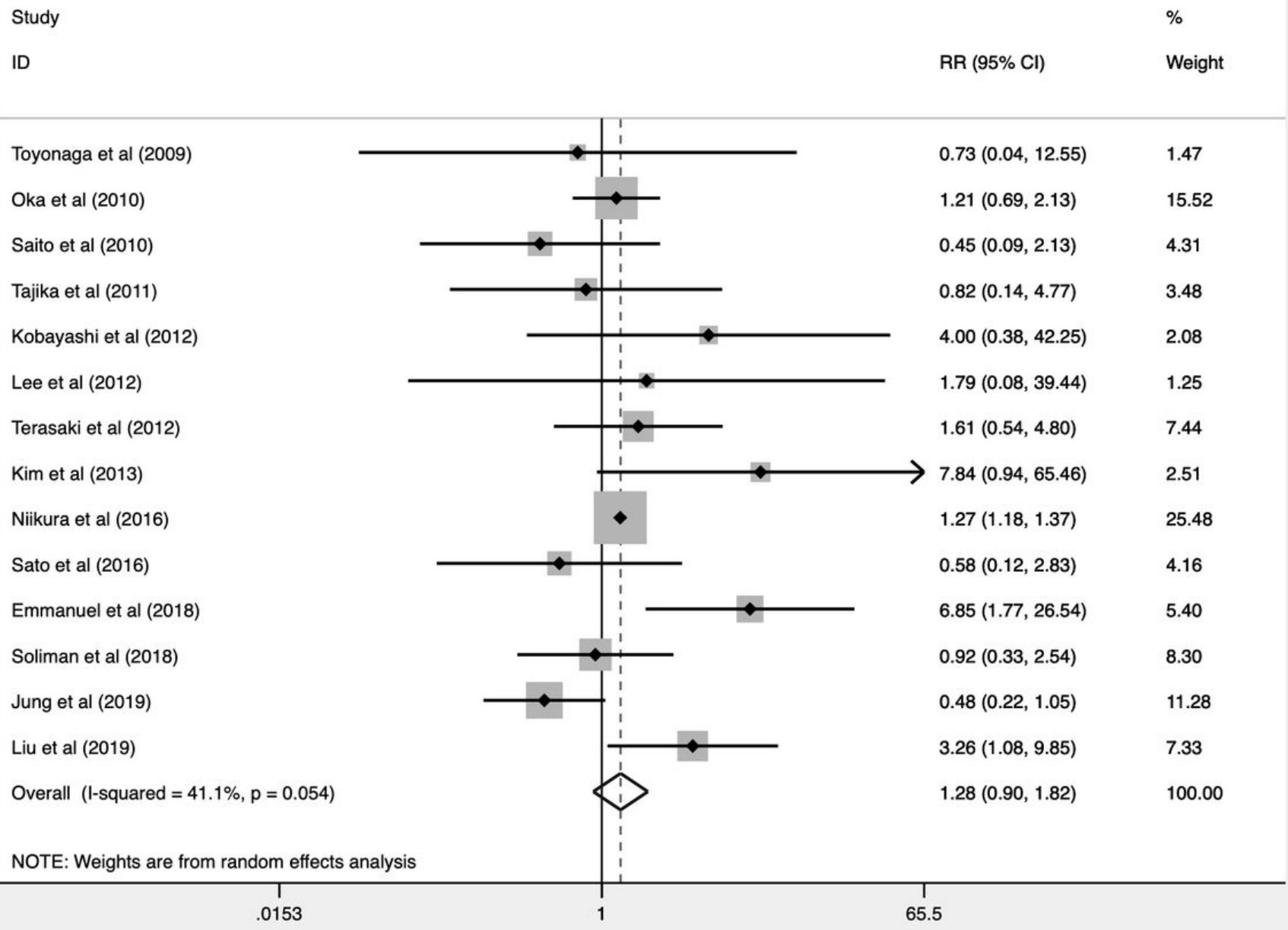

\section{Figure 3}

Forest plot for risk of bleeding 
Study

ID
$\%$

$\mathrm{RR}(95 \% \mathrm{Cl})$

Weight

$0.11(0.01,2.41)$

4.96

$1.70(1.04,2.78)$

12.16

$0.14(0.04,0.46)$

10.34

$0.08(0.01,0.56)$

7.63

$0.08(0.01,1.34)$

5.55

$0.03(0.01,0.12)$

9.51

$0.61(0.02,17.87)$

4.40

$3.16(0.11,92.56)$

4.40

$0.43(0.12,1.52)$

10.05

$0.30(0.08,1.22)$

9.61

$0.50(0.27,0.94)$

11.87

$0.21(0.05,0.88)$

9.51

$0.27(0.11,0.65)$

100.00

Overall $(\mathrm{l}$-squared $=81.1 \%, \mathrm{p}=0.000)$

NOTE: Weights are from random effects analysis

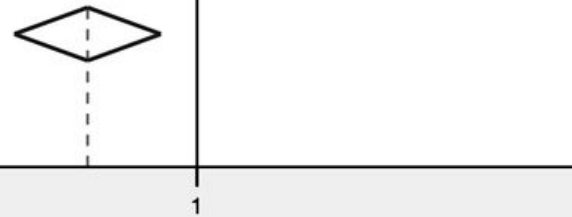

\section{Figure 4}

Forest plot for recurrence rate 


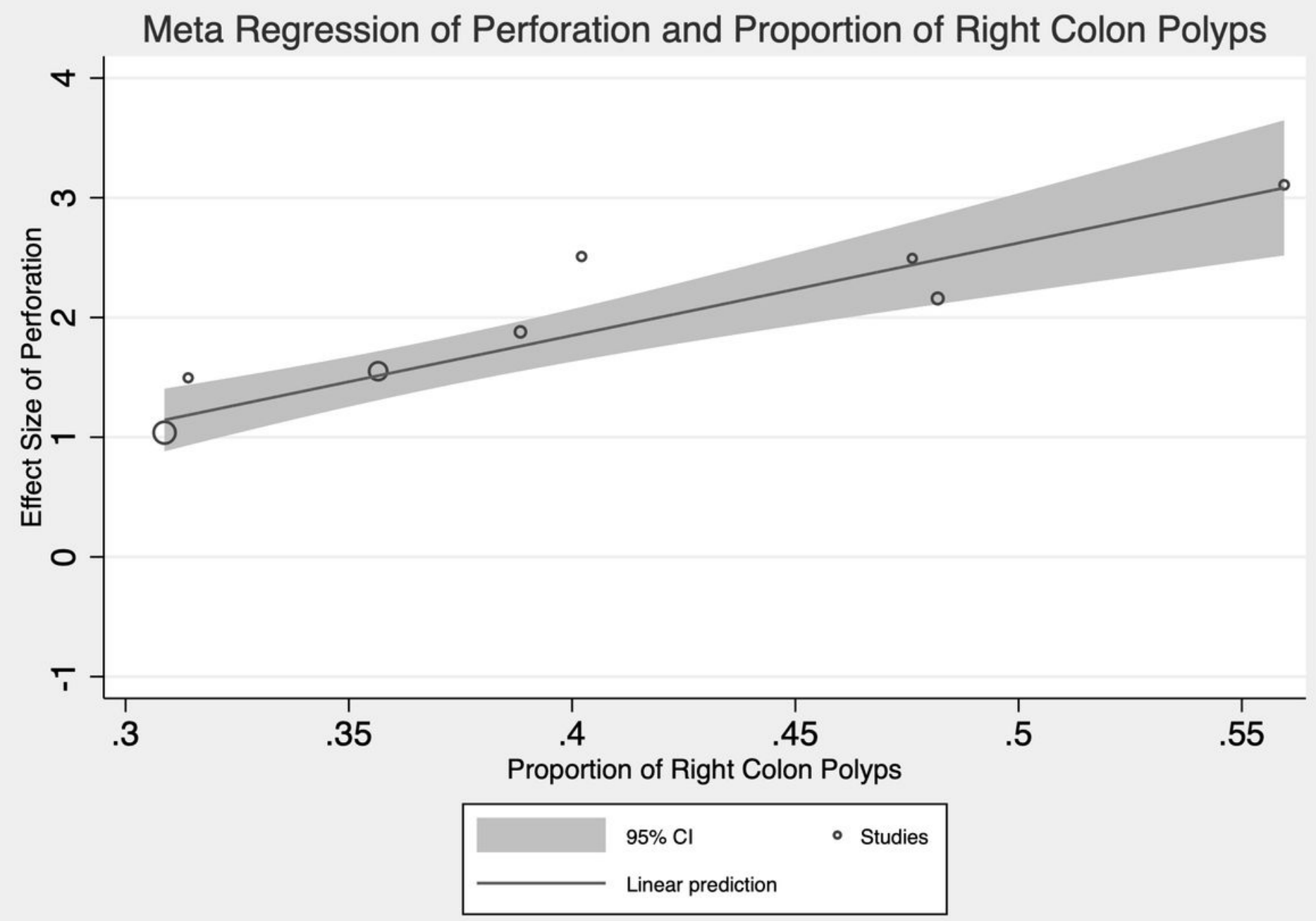

Figure 5

Meta regression of perforation and proportion of right colon polyps

\section{Supplementary Files}

This is a list of supplementary files associated with this preprint. Click to download.

- SupplementaryMaterial1.docx

- SupplementaryMaterial2.docx

- SupplementaryMaterial3.docx 